\title{
Ultrasonic Quasi-Rayleigh Waves - Propagation Properties and Detection of Mechanical Damage
}

\author{
Michal Hlavatý ${ }^{1, *}$, Miloš Musil ${ }^{1}$, Branislav Hučko ${ }^{1}$ \\ ${ }^{1}$ Institute of Applied Mechanics and Mechatronics, Faculty of Mechanical Engineering, Slovak University of Technology, Námestie slobody 17, 81231 \\ Bratislava, Slovakia
}

\begin{abstract}
This article examines the propagation of quasi-Rayleigh waves and their trial application to detect defects in plate structures. With their specific propagation properties, quasi-Rayleigh waves have the potential to extend the scope of conventional ultrasound defect detection methods. This would enable detection across longer distances and with higher sensitivity, with earlier identification of surface defects in plate structures as a result. The article contains a basic description of quasi-Rayleigh waves, together with their propagation properties, with respect to a particular isotropic material (steel). The propagation of quasi-Rayleigh waves is then demonstrated using a smooth plate and a plate featuring a unilateral obstacle. The behaviours of propagating waves are determined using three approaches: analytical, numeric and experimental. The last part of the article provides a diagram and a description of the experimental measurement assembly and a case of detecting a surface defect in a plate structural part.
\end{abstract}

Keywords: ultrasonic; quasi-Rayleigh waves; dispersion; steel plate; surface defect.

\section{Introduction}

Ultrasound methods used to detect mechanical defects of materials have found uses across a wide range of applications. They enable the detection of surface or internal faults (flaws, cavities, cracks, etc.) in materials. One advantage of ultrasound detection methods is their non-destructive nature (i.e. no destruction of the tested material is necessary). This is the ground for the employment of ultrasound methods in off-line or on-line detection of mechanical faults. Relatively small sizes of measurement apparatuses and a high rate of use of electrical circuits are a benefit in terms of dimensional, installation and user requirements. Another important positive factor is safety: the rates at which ultrasound is used are not harmful to operators' health. All the positive points mentioned above contribute to the wide use of ultrasound methods in material defect detection applications.

The conventional ultrasound detection of defects (in welded joints, castings, etc.) relies on bulk waves whose distance reach is limited. Recently, the scientific community has focused its attention on so-called guided waves, i.e. waves propagating within an environment that is limited along one or two axes (bars, plate structural elements, etc...). This type of wave is basically able to propagate over extended distances with lower energy attenuation than bulk waves. This potentially allows the extension of defect detection possibilities for structural parts. Moreover, some guided waves (such as Rayleigh waves and Lamb waves) present higher 
sensitivity to surface defects (fatigue flaws) than bulk waves [1], [2]. This allows their employment in systems for the continuous detection of defects of critical structural parts in the course of operation [3].

So-called quasi-Rayleigh waves are also categorised as guided waves. They propagate in beam and plate structural elements [4]. This wave type corresponds to the transition area between Lamb and Rayleigh waves. In addition to their ability to propagate to relatively long distances, another important feature of quasi-Rayleigh waves is periodical transmission of wave energy between the surfaces of a beam or plate. Hence with a suitable frequency design, quasi-Rayleigh waves are able to overcome regularly spaced unilateral obstacles such as reinforcement elements, crosspieces, etc. [5]. This property may potentially allow extension of the application range of ultrasound detection methods to geometrically more complex (beam or plate) elements (e.g. aviation structures [6]).

\section{Quasi-Rayleigh waves}

Quasi-Rayleigh waves as a term designate waves that are the superposition of fundamental symmetric (So) and anti-symmetric (Ao) modes of a Rayleigh-Lamb wave in the region of certain frequencies [7]. The "quasi" prefix denotes that the form of quasi-Rayleigh waves is nearly identical to Rayleigh waves in an infinite half-space. However, the propagation properties of the two wave types are different: while Rayleigh waves are dispersionless in an infinite space, the propagation of quasi-Rayleigh waves is influenced by dispersion. The dispersion causes splitting of the symmetrical and anti-symmetric modes of Rayleigh-Lamb waves, as well as periodical transmission of the main wave energy between the upper and lower edges of the plate (Fig. 1).

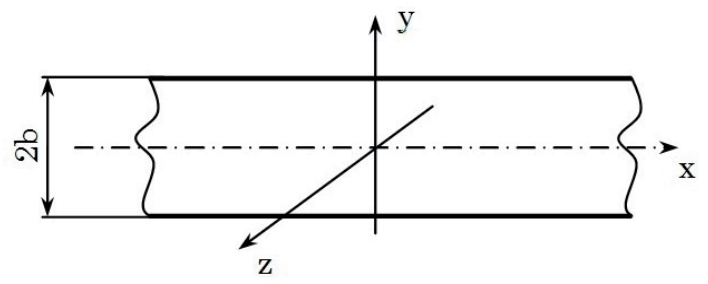

Fig. 1: Theoretical two dimensional infinite model of the plate.
Further, the So and Ao modes feature the simplest displacements and tensions within the plate thickness of all Rayleigh-Lamb modes. Fig. 2 shows the summations of symmetric and anti-symmetric modes for different fundamental wave frequencies. The summations of displacement amplitudes indicate that starting from a certain frequency region (approx. $6 \mathrm{MHz} . \mathrm{mm}$ for steel; Tab.1), the resulting $\mathrm{So}+\mathrm{A}_{0}$ forms are very similar (nearly identical) to the displacements of theoretical Rayleigh waves. As an important feature, the main wave energy of these waveforms is contained within the plate thickness (the interval from $-b$ to $+b$ ). The upper side of the plate $(+b)$ contains only negligible displacements.

Tab. 1: Material properties of steel.

\begin{tabular}{|l|l|}
\hline Young's modulus [ GPa ] & 210 \\
\hline Poisson's ratio & 0.3 \\
\hline Density $\left[\mathrm{kg} \cdot \mathrm{m}^{-3}\right]$ & 7850 \\
\hline
\end{tabular}

As the waves propagate across the thickness, the summary So + Ao waveforms gradually change. This is due to the fact that the phase velocity of the symmetric mode is always higher than the phase velocity of the anti-symmetric mode (Fig. 2; Phase velocity of wave diagram - the bottom right). The separate So wave thus propagates ahead of A0. This causes the $S_{0}+$ Ao waveform to change, and after certain distance, the So + Ao waveform reverses around the central axis of the plate (Fig. 3b). A smooth reversal of the $S_{0}+A_{0}$ waveform occurs in the course of further propagation (Fig. 3c) and the summary waveform re-acquires its initial shape and form (Fig. 3a). The reversal of the So + Ao waveform recurs periodically with the interval of $2 \pi$. The distance at which the summary waveform repeats (after the said interval) is referred to as 'beat-length' and is calculated as follows [5]:

$L_{b}=\frac{2 \pi}{\xi_{A 0}-\xi_{S 0}}$

where: $\boldsymbol{\xi}_{\text {so }}$ - wavenumber of the symmetric mode $\left[\mathrm{m}^{-1}\right], \boldsymbol{\xi}_{A 0}$ - wavenumber of the anti-symmetric mode (common frequency for $\boldsymbol{\xi}_{\text {So }}$ and $\boldsymbol{\xi}_{A 0}$ ) $\left[\mathrm{m}^{-1}\right]$.

As the wavenumbers, $\boldsymbol{\xi}_{\text {So }}$ and $\boldsymbol{\xi}_{A 0}$, are assigned to the product of frequency and plate thickness $\left(f^{*} 2 b\right)$, the beat-length value is also a function of $f * 2 b$. The beat-length - frequency functions corresponding to 


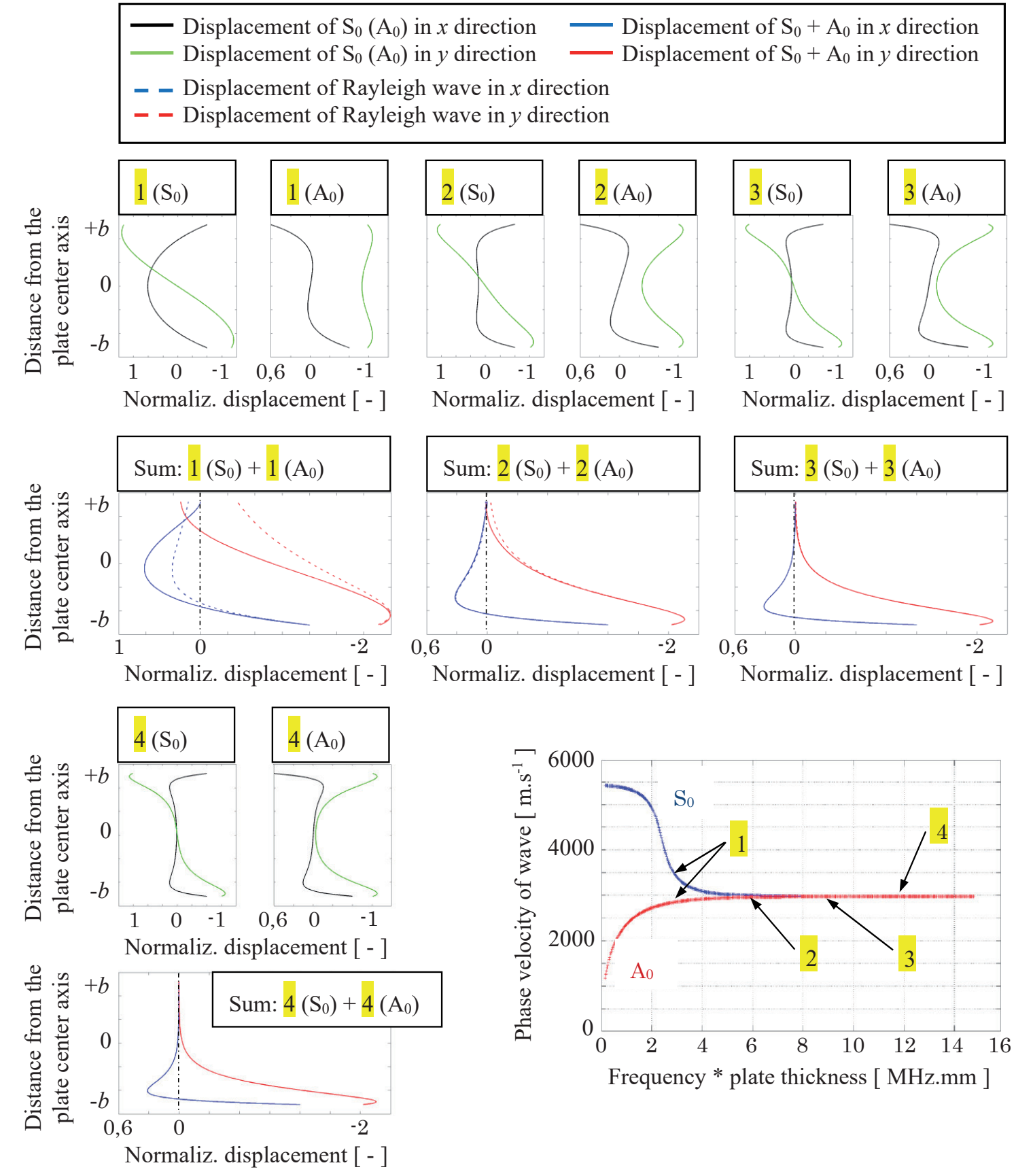

Fig. 2: Representation of the resulting So + Ao modes for the selected frequency*thickness products (material properties of steel from Tab. 1).

the steel material properties (Tab.1) are represented in Fig. 4. Starting from $2.5 \mathrm{MHz}$.mm, the beat-length values are nearly exponential. For example, for the plate thickness of $4.19 \mathrm{~mm}$, starting from $8.5 \mathrm{MHz}$. $\mathrm{mm}, L_{b}>1 \mathrm{~m}$; and from $12 \mathrm{MHz} \cdot \mathrm{mm}$, $L_{b}$ equals to tens of metres. The range of frequencies $f^{*} 2 b$ values for which the transmission of $\mathrm{S}_{0}+$ Ao waves from one side of the plate to another is used for NDT purposes (Fig. 3) corresponds to quasi-Rayleigh waves [4], [5]. And, at the same time, the So + Ao waveform is very similar to the Rayleigh waveform in an infinite half-space (Fig. 2). These two characteristics enable 
overcoming of one-side obstacles and two-side detection of surface defects of plates.

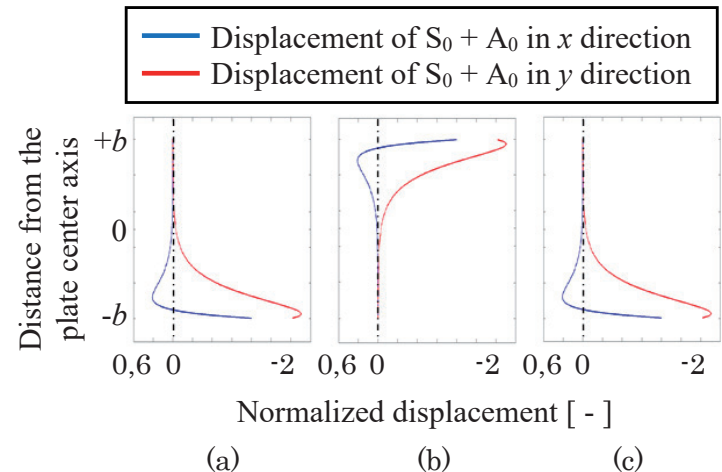

Fig. 3: Representation of the resulting So + Ao modes at distance $x$ from the starting point of wave propagation: (a) $x=0 \mathrm{~m}$; (b) $x=$ $L b / 2 ;(c) x=L b$.

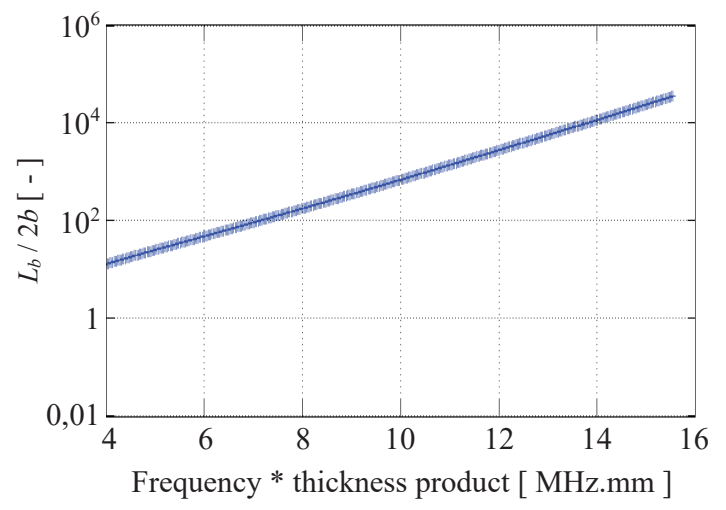

Fig. 4: Beat-length as a function of frequency*thickness product.

\section{Propagation of quasi-Rayleigh waves}

The propagation of quasi-Rayleigh waves is determined by the properties of symmetric and anti-symmetric Rayleigh-Lamb wave modes. Besides differences in phase velocities, So and Ao also show different group velocity values. This causes the splitting of the $S_{0}+A_{0}$ impulse wave package into separate impulses $S_{0}$ and $A_{0}$ (as the wave propagates, the Ao mode overruns the So mode). This effect is represented in Figs.7 (a) and 8(a) which compare the individual So and Ao modes.

The propagation of quasi-Rayleigh waves in plate structures is demonstrated by the waveform results obtained analytically, numerically (FEM) and experimentally. The excitation of quasi-Rayleigh waves in each of the three cases was provided by a harmonic wave signal, modulated by the Hann window. The signal waveform may be represented as follows:

$$
y(t)=A_{b} F(t)\left[0,5-0,5 \cos \left(2 \pi f_{H} t\right)\right]
$$

where: $A_{b}$ - amplitude of the excitation signal [ - ], $F(t)$ - harmonic wave function [ -$], f_{H}-$ frequency of Hann window $[\mathrm{Hz}], t$ - time [ $\mathrm{s}]$.

Further analysis is based on the use of a harmonic excitation signal with the fundamental frequency, $f_{0}$ of $1.55 \mathrm{MHz}$ with 20-cycle Hann modulation ( $f_{H}=$ $f_{0} / 20=77.5 \mathrm{kHz}$ ). The signal waveform is shown in Fig. 5. The reason for the use of a Hann-modulated signal is the fact that the main amplitude content in the spectral region is concentrated within the width of the main lobe. Then, the sidelobe amplitudes have no major effect on the shape of the impulse, which reduces the dispersion of the propagating signal as a result.

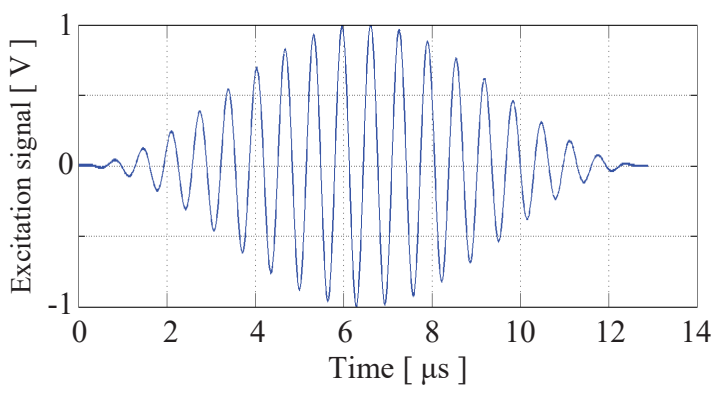

Fig. 5: Excitation signal.

The analytical shapes of quasi-Rayleigh waves are determined using the Fourier integral formula [8]:

$\psi(t, x)=\int_{\omega=0}^{\infty}\left\{\begin{array}{l}A(\omega) \sin [\omega t-\xi(\omega) x]+ \\ +B(\omega) \cos [\omega t-\xi(\omega) x]\end{array}\right\} d \omega$

where

$A(\omega)=\frac{1}{\pi} \int_{-\infty}^{\infty} \psi(t) \sin (\omega t) d t$

$B(\omega)=\frac{1}{\pi} \int_{-\infty}^{\infty} \psi(t) \cos (\omega t) d t$

$x$ - distance in the propagation direction [m], $\omega$ - angular velocity [rad], $\xi(\omega)$ - approximation polynomial of the dispersion curve $\left[\mathrm{m}^{-1}\right], \psi(t)-$ waveform in distance $x=0$ [-] (excitation signal). 
The required waves were calculated in MATLAB using numerical integration of the equation (3). The approximation polynomial substitutes wave values in the frequency interval which corresponds to the width of the main spectral lobe of the impulse [7].

Further waves were obtained using the FEM method and experimental measurements. The FEM calculation was executed over a 2D model of a $4.19 \mathrm{~mm}$ thick plate (ANSYS; plain strain problem; no material attenuation considered). The $\mathrm{S}_{0}+\mathrm{A}_{0}$ waves were generated in the model by kinematic excitation applied to the front end of the plate. Modelling principles followed in wave-related problems differ from those applicable to structural problems [10]. The finite element type and size and the time step are chosen with regard to sufficient accuracy of the calculation in terms of numerical dispersion and period error [9]:

$\checkmark$ element type: PLANE 183

$\checkmark$ element size: $\Delta l=8,38 \cdot 10^{-5} \mathrm{~m}$

$\checkmark$ time step: $\Delta t=7,016.10^{-9} \mathrm{~s}$

The experimental measurement results were obtained through a measurement assembly using

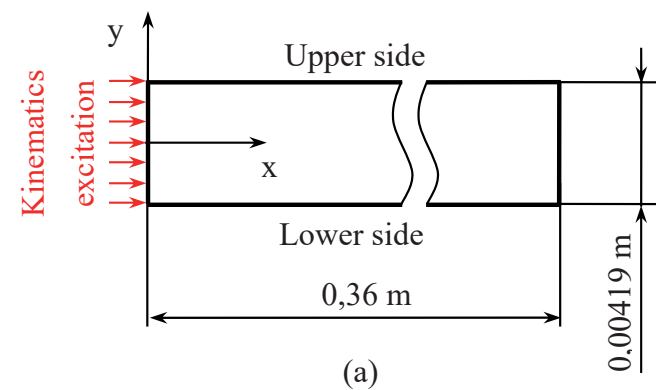

(a)

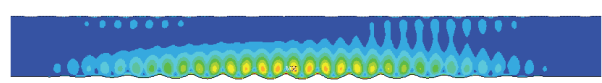

(c) ultrasound transducers and angle-beam wedge transducers (Fig. 11). The output from the measuring was the stress values corresponding to the surface (generally Rayleigh-Lamb) waves in the material sample.

\subsection{Propagation of quasi-Rayleigh waves in even plate}

The propagation of quasi-Rayleigh waves in an even plate is the simplest case for the comparison of waves obtained from analytical, numerical (FEM) and experimental exercises. The FEM calculation model for an even plate is shown in Fig. 6(a). A graphical representation of propagating quasi-Rayleigh waves along the even plate is in Fig. $6(b-d)$. It confirms that the periodical transmission of wave energy between the sides of the plate agrees with the theoretical assumptions (Fig. 3). Immediately after the excitation of waves, the main wave energy of $\mathrm{S}_{0}+$ $A_{0}$ is concentrated in the upper part of the plate (Fig. $6(b))$; after the distance $L_{b} / 2\left(L_{b}=0.2774 \mathrm{~m}\right)$, wave energy is concentrated in the lower part of the plate (Fig. 6(c)). After the distance $L b$, wave energy again concentrates in the upper part of the plat (Fig. 6(d)). The cycle continues to repeat periodically.

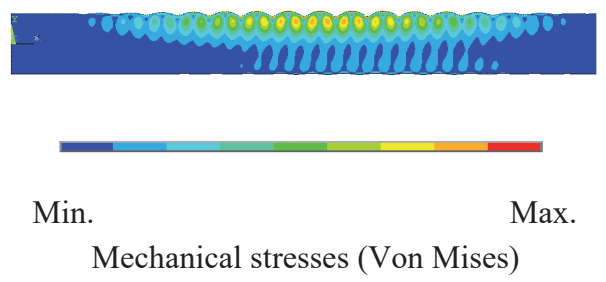

(b)

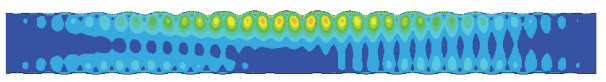

(d)

Fig. 6: (a) Diagram of the finite element model of even plate; Von Mises stresses: (b) after wave excitation $(x \approx 0 \mathrm{~m})$, (c) for position $x \approx L b / 2$, (d) for position $x \approx L$.

Figs. 7 and 8 show the time behaviours of waves (analytical, FEM and experimental) observed at the plate surfaces at a distance of approx. Lo from excitation. Another obvious fact is faster incidence of the Ao mode due to its higher group velocity: the Ao mode propagates ahead of So. A comparison of the analytical results and FEM results (Fig. 7(b), 8(b)) indicates practically identical behaviours of $\mathrm{S}_{0}+\mathrm{A}_{0}$. This comparison confirms sufficient accuracy of the proposed FEM model (propagation to a distance $I \approx L_{b}$ is assumed). The FEM model may also be used for further, more complex calculations, e.g. for purposes of exploring the interaction between quasi-Rayleigh waves and the surface discontinuity/ fault considered. The experimental measurement results are summarised in Figs. 7(c) and 8(c). The waves feature the same characteristics as those resulting from the analytical and FEM calculations 
(a)

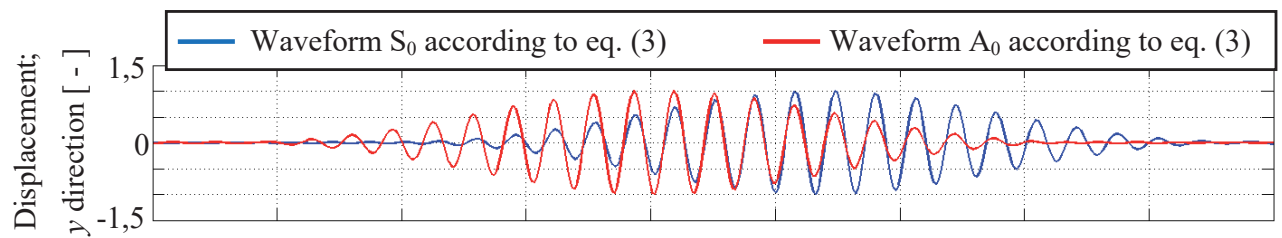

(b)

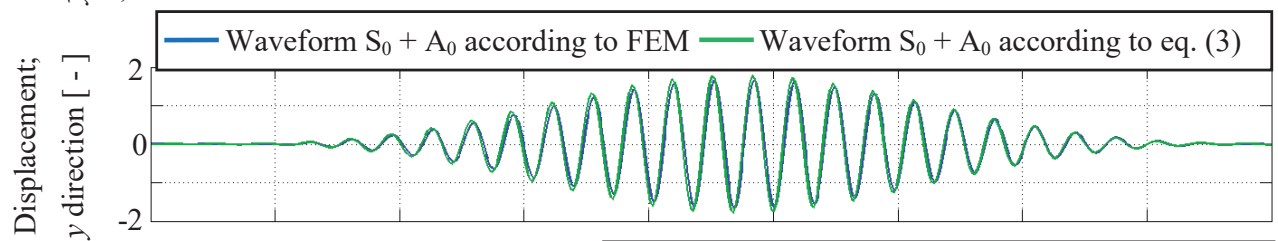

(c)

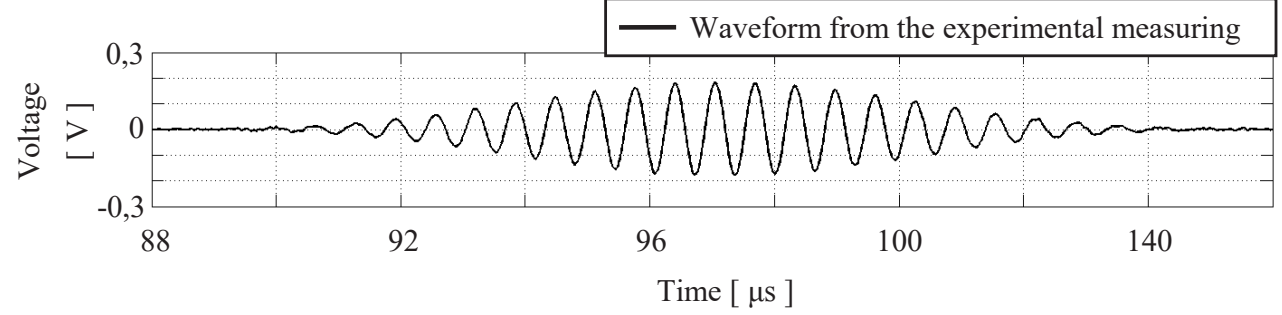

Fig. 7: Waveforms in position $x=$ Lb from excitation point, on the upper side of even plate ( $y=b$; according to Fig. 1): (a) analytical waveforms So, $A_{0}$, (b) analytical waveform So + Ao and waveform from the finite element model in Fig.6(a), (c) waveform from experimental measuring.

(a)

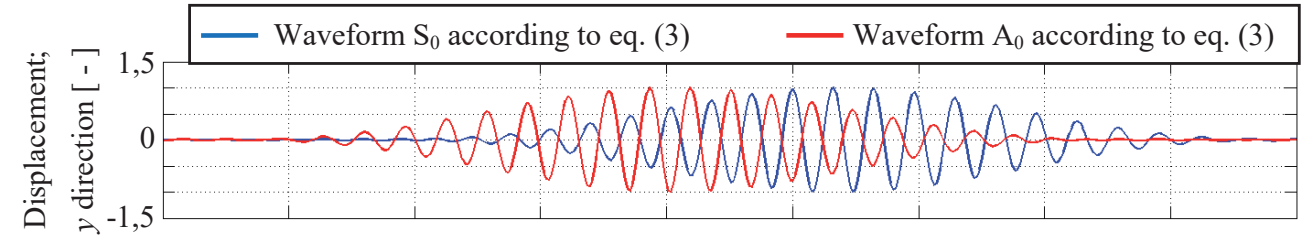

(b)

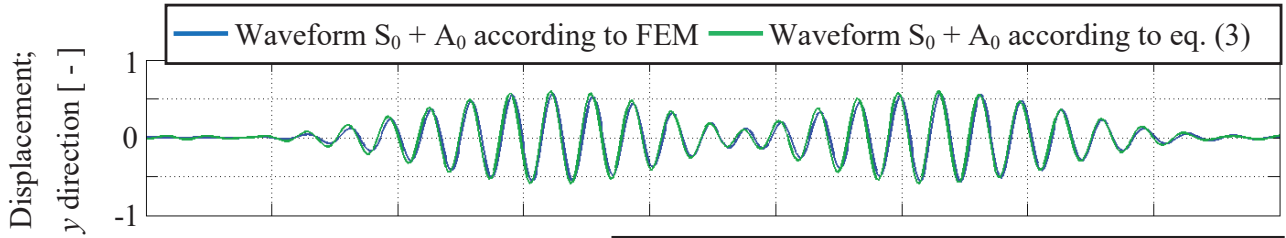

(c)

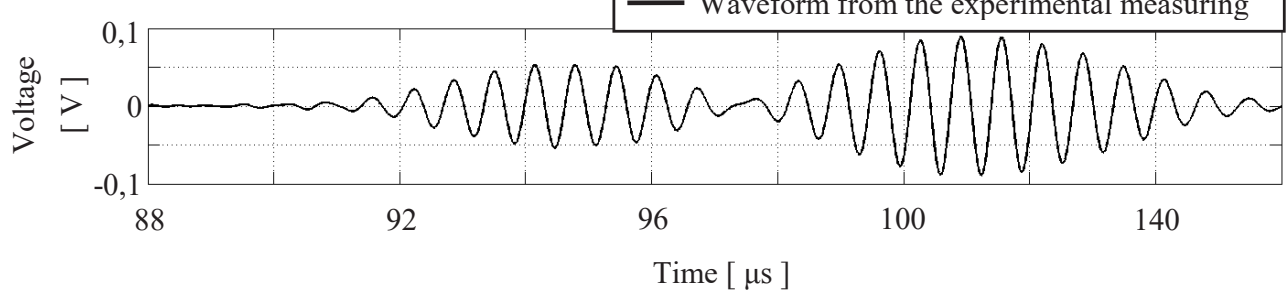

Fig. 8: Waveforms in position $x=$ Lb from excitation point, on the lower side of even plate ( $y=-b$; according to Fig. 1): (a) analytical waveforms $S_{0}, A_{0}$, (b) analytical waveform So + Ao and waveform from the finite element model in Fig.6(a), (c) waveform from experimental measuring.

(test plate thickness of $2 b \approx 4.19 \mathrm{~mm}$ ). Hence the experimental measurement assembly conforms to the requirement for excitation and sensing of quasiRayleigh waves within a given frequency range. This is also proven by the peak-to-peak amplitudes of the signal measured along the smooth plate
(Fig. 10), which indicates the periodical transmission of wave energy between the plate surfaces.

\subsection{Propagation of quasi-Rayleigh waves in plate with crosspiece}

The propagation of quasi-Rayleigh waves in plates with cross-pieces is affected by the presence of elements interrupting the continuousness of 
surface (separating walls, reinforcements, etc.). Such elements cause partial dispersion of wave energy, while they have nearly no effect on the beat-length, Lb. An example of interaction between quasiRayleigh waves and a unilateral crosspiece is shown in Fig. 9 (FEM calculation). In this case, the impulse is reduced to 5 cycles so that the impulse edges form separate $S_{0}$ and Ao modes (impulse splitting due to different group velocities). The unilateral crosspiece is located at a distance $x=L b / 2$ from excitation and the theoretical minimum of wave energy is incident on the part where it crosses the plate. The crosspiece induces the dispersion of waves in the upper part of the plate, while the lower part of waves bypasses the plate with a small decrease in amplitudes.

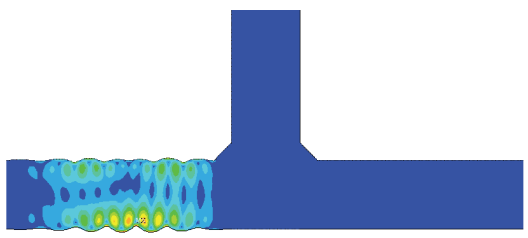

(a)

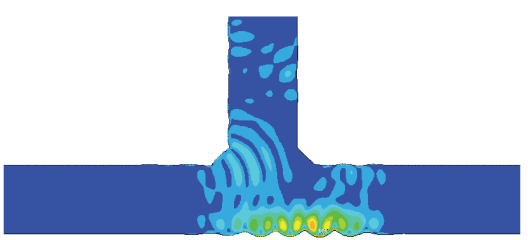

(c)
Quasi-Rayleigh waves are thus able to overcome unilateral crosspieces with an acceptable degree of energy attenuation. This applies, however, only if the crosspiece is located in the place where wave energy is minimal (e.g. $L b / 2,3 / 2 L b, 5 / 2 L b$...). Peak-to-peak amplitudes of waves along the plate are then nearly the same for both an even plate and a plate with a crosspiece (Fig. 10). Quasi-Rayleigh waves are thus able to propagate over longer distances without any significant attenuation. When the crosspieces are located in places other than those with minimum wave energy, the attenuation significantly increases [6]. This is due to the fact that higher wave energy is incident in the region of the crosspiece, and it disperses and its amplitude becomes lower.

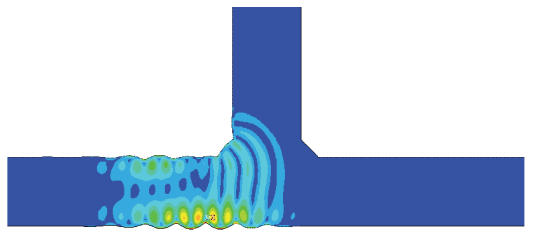

(b)

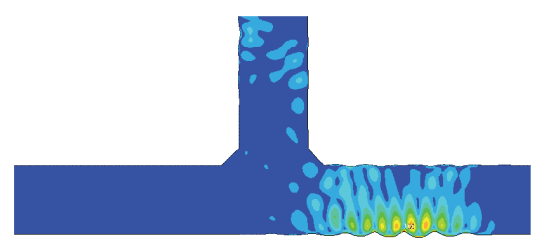

(d)

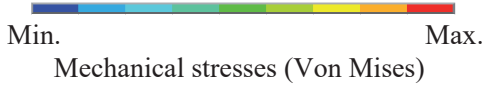

Fig. 9: Quasi-Rayleigh waves view as mechanical stresses in the crosspiece part of FEM (5-cycles impulse excitation): (a) time: 4,56.10-5 s; (b) time: 4,7.10-5 s; (c) time: 4,91.10-5 s; (d) time: 5,09.10-5 s

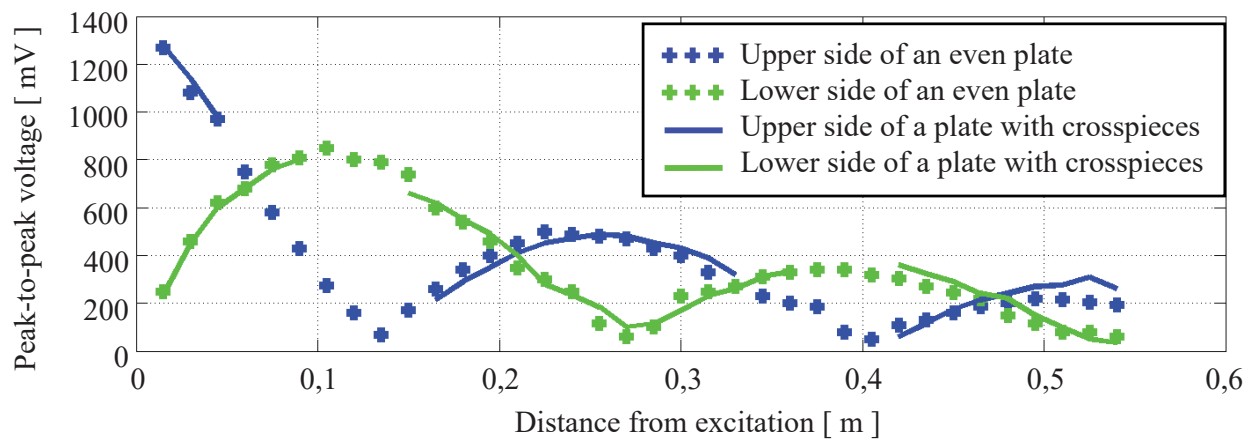

Fig. 10: Peak-to-peak voltage curves for the even plate and the crosspieces plate of the same thickness $\left(2 b=4,19 \mathrm{~mm}, f_{0}=1,55 \mathrm{MHz}, \mathrm{Lb}=\right.$ 0,2774 m, 20-cycles impulse); the thickness of crosspieces is same as the plate thickness; the crosspieces are located at the distance 0,135 $m$ and $0,405 m$ from excitation. 


\section{Experimental equipment and failure detection}

The measurement assembly used in the observation of propagation of quasi-Rayleigh waves in the samples (Fig. 7(c), Fig. 8(c) and Fig. 10) and the experimental detection of defect (Fig. 12 and Fig. 13) are schematically outlined in Fig. 11 [7]. The excitation and sensing of quasi-Rayleigh waves was done by means of angle beam wedge transducers (Videoscan V551-SM transducers, ABWML-7T-90 angle beam wedges). The measurement sequence was controlled by an algorithm programmed in NI LabView Development System. The algorithm allows the synchronised excitation and sensing of ultrasound waves, together with the storage and preevaluation of measured signals. The measurement signal contains separate digital oscillator and oscilloscope, due to which it is impossible to concurrently use separate transducers for the excitation and the sensing of waves. Therefore, the transmitter and the receiver are placed close to each other for the reflection measurement (Fig. 12(b)).

The trial application of quasi-Rayleigh waves to detect a surface defect in a plate structure is schematically outlined in Fig. 12(a). The defect is a perpendicular slot made from the upper side of a steel welded plate (plate thickness is $2 b=5.2 \mathrm{~mm}$, plate width is $0.2 \mathrm{~m}$ ) and gradually deepening. This type of defect simulates a flaw or other defect extending perpendicularly to the plate surface. The slot is located at a distance $L_{b}$ of approximately $0.27 \mathrm{~m}$ from the transducer (the wave frequency is $f_{0}=1.17 \mathrm{MHz}$ ); the crosspiece is located at the distance $L_{b} / 2=0.135 \mathrm{~m}$ from the transducer. The location of the perpendicular slot was chosen with regard to the fact that the maximum of wave energy is concentrated at the distance $L$ b. This is thus an ideal case for trial detection, since maximum wave energy is incident in the region of the potential flaw.

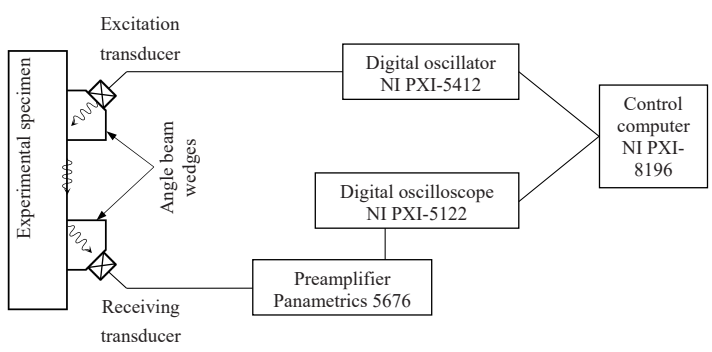

Fig. 11: Diagram of the measurement assembly.
The parameter chosen for detection evaluation is the peak-to-peak amplitude of the measured signal, yPtP. The measurement at the fundamental frequency $f_{0}=1.17 \mathrm{MHz}$ was done by two impulses with 5-cycle and 20-cycle Hann modulation. The values of $y_{p t p}$ as a function of the slot depth to plate thickness ratio ( $\left.h_{d} / 2 b\right)$ are shown in Fig. 13. It is obvious from the Figure that the peak-to-peak amplitude of the signal rises from $h_{d} / 2 b<0.05$, which suggests early detection of a surface defect. The experiment thus confirms the suitability of quasi-Rayleigh waves for use in the detection of surface defects, even over longer distances. An increase in $y_{p t p}$ is obvious for both modulation cases. For the 20-cycle modulation, yptp values are higher, which is attributable to the concentration of more wave energy around $f_{0}$. For values of $h_{d} / 2 b>0.1$, the rise in yPtP values is more modest, or they even temporarily decrease. This is because of shear or longitudinal standing waves formed at values of $h_{d} / 2 b>0.1$ in the wave-cut interaction. Such standing waves are formed if so-called cut-off frequencies are present in the spectral band of impulses [5], [9]. The effects of such frequencies impede or even prevent accurate quantification of the perpendicular cut depth.

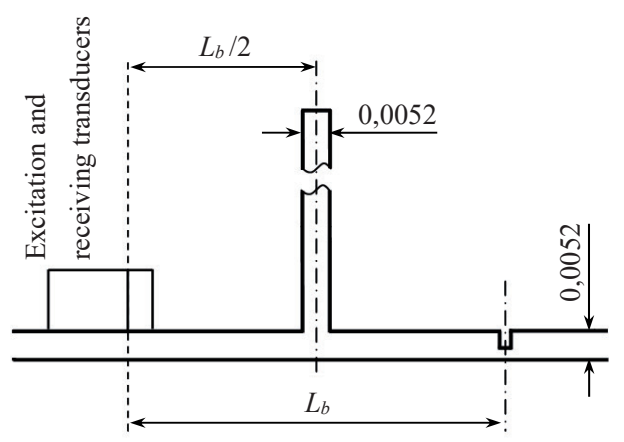

(a)

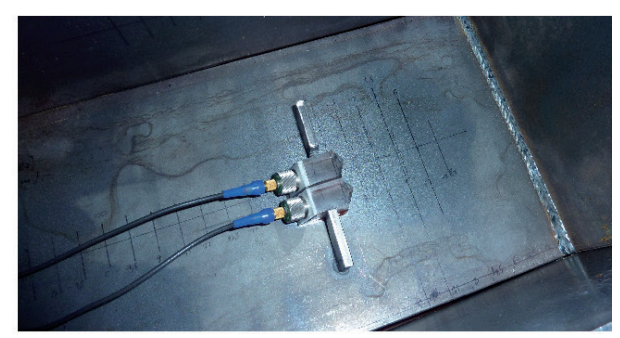

(b)

Fig. 12: (a) Diagram of the test set-up ; (b) Localization of excitation and receiving transducers. 


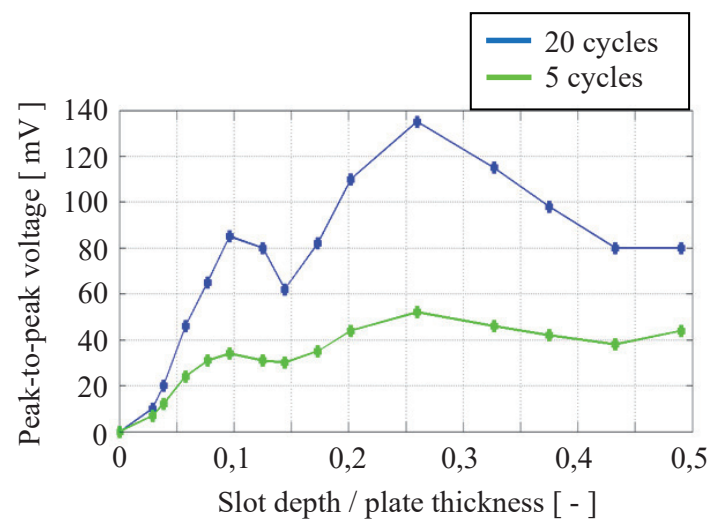

Fig. 13: Peak-to-peak voltage curves as function slot depth / plate thickness.

\section{Conclusions}

With their ability to overcome unilateral crosspieces, quasi-Rayleigh waves enlarge the extent of application of ultrasound defect detection methods. This is allowed by the transmission of the aggregate wave energy of the fundamental symmetric ( $\left.S_{0}\right)$ and anti-symmetric $\left(A_{0}\right)$ modes or Rayleigh-Lamb waves (the waveform of $\mathrm{So}_{+}+\mathrm{A}_{0}$ is similar to that of theoretical Rayleigh waves) through the plate thickness. The periodicity of this wave energy transmission depends on the wave frequency, and this allows suitable setting of the beat-length, Lb so that the waves are able to overcome a crosspiece or crosspieces with minimum wave attenuation. One proven impulse excitation method is Hann modulation: it concentrates the main amplitude content of an impulse within the frequency width of the main lobe (which helps to supress dispersion). The finite element method is an instrument that helps to predict, as an example, wave propagation in geometrically more complex mechanical continua, or interaction with a mechanical defect. This enables further research into the potential uses of quasi-Rayleigh waves or other types of waves. Physical model settings differ from settings of a structural problem model: in addition to providing a sufficiently dense sample set, it is also necessary to consider numerical dispersion. The correctness of FEM model settings can be validated, in simplest cases, by means of dispersion curve data (wavenumbers, phase/group velocities), or by determining the time behaviour of waves using the Fourier integral.

The suitability of a particular measurement sequence for quasi-Rayleigh wave excitation and sensing purposes is verifiable by measuring peakto-peak amplitudes of waves along the both plate surfaces. The curve of peak-to-peak amplitudes is characterised by periodical rises and drops along the plate, with local minimum intervals corresponding to the beat-length, Lb. As an ideal case, where the unilateral crosspieces are positioned in a location of peak-to-peak minima, the curves of peak-to-peak amplitudes for the even plate and the plate with a crosspiece are approximately identical. A case with the simulated defect (perpendicular slot) originating and extending in a peak-to-peak maximum location was examined in the experimental defect detection exercise. In this case, early detection of the defect (slot depth $<5 \%$ plate depth) was observed, which confirms the suitability of quasi-Rayleigh waves for application in detection of defects of this type and location. The method is, however, not quite suitable for the quantification of a defect (cut depth), which is due to the complexity of the mechanism of interaction of quasi-Rayleigh waves with surface discontinuities.

\section{Acknowledgments}

This work was supported by the Slovak Research and Development Agency under the contract no. APVV-15-0630.

\section{References and Notes}

[1] Harri, K., Guillaume, P., Vanlanduit, S. (2006). On-line monitoring of cracks using ultrasonic multisine surface waves, 9th European Conference on Non-destructive testing, Berlin, ISBN 3-931381-86-2

[2] Terrien, N., et. al. (2007). A combined finite element and modal decomposition method to study the interaction of Lamb modes with micro-defect, Ultrasonic 46 (2007), p.7488, ISSN 0041-624X

[3] Krššák, P. (2008). Detekcia porúch v kmitajúcich mechanických sústavách, Dizertačná práca, Strojnícka fakulta STU v Bratislave, 2008, SjF-10940-10281

[4] Viktorov, I. A. (1967): Rayleigh and Lamb waves: Physical theory and applications, Plenum Press, New York, ISBN 9781-4899-5683-5

[5] Masserey, B., Fromme, P. (2008). On the reflection of coupled Rayleigh-like waves at surface defects in plates, J. Acoust. Soc. Am 123 (1), January 2008, p. 88-98, ISSN 1520-8524

[6] Masserey, B., Fromme, P. (2009). Surface defect detection in stiffened plate structures using Rayleigh-like waves, NDT\&E International 42 (2009), p. 564-572, ISSN 0963-8695

[7] Hlavatý, M. (2017). Ultrazvuková detekcia poškodenia me- 
chanických systémov, Dizertačná práca, Strojnícka fakulta STU v Bratislave, 2017, SjF-10941-26820

[8] Crawford, F. S. (1968). Waves Berkeley physics course, McGraw-Hill, Vol.3, New York

[9] Hlavatý, M., Starek, L., Musil, M., Hučko, B. (2017). Ultrasonic defect detection of structural plates using quasi-Rayleigh waves, Journal of mechanical engineering = Strojnícky časopis, Vol. 67 (2017), No. 2, p.37-50, ISSN 2450-5471

[10] Musil, M. (2006). Localization and quantification of breathing crack. In: Journal of Dynamic Systems Measurement and Control-Transactions of the ASME, Vol. 128, No. 2 (2006), p. 458-462, ISSN 0022-0434

[11] Écsi, L., Élesztős, P., Jančo, R. (2016). On the stress solution of hypoelastic material based models using objective stress rates, APLIMAT 2016 - 15th Conference on Applied Mathematics 2016, Proceedings, Bratislava, 2 - 4 February 2016, p. 280-297, ISBN: 978-802274531-4

[12] Frydrýšek, K., Jančo, R. (2016). Simple planar truss (linear, nonlinear and stochastic approach), In Strojnícky časopis = Journal of mechanical engineering, Vol. 66, No.2, 2016, p. 5 - 12, DOI: 10.1515/scjme-2016-0013

[13] Chmelko, V. (2015). Vrubové účinky v prevádzke strojov a konštrukcií, Vydavatel'stvo STU, ISBN: 978-80-227-4482-9

[14] Chmelko, V., Kliman, V., Garan, M. (2015). In-time monitoring of fatigue damage, In Procedia Engineering 101, Elsevier 2015, p. 93-100

[15] Musil, M. (2001). Crack localization and quantification, In Strojnícky časopis = Journal of mechanical engineering, Vol. 52, No. 5-6 (2001), p. 103, ISSN 0039-2472

\section{Biographical notes}

Ing. Michal Hlavatý, Ph.D., received PhD. degree on Institute of Applied Mechanics, Faculty of Mechanical Engineering, Slovak University of Technology in Bratislava, in 2017. His dissertation thesis deals with application of ultrasonic method for structural defect detection in steel plates.

prof. Miloš Musil, Ph.D., is a professor in Faculty of Mechanical Engineering at Slovak University of Technology in Bratislava. His research interests are dynamics of machines, their active and passive vibration insulation, experimental parameters identification and correction of mathematical models of mechanical and mechatronic systems, as applied. In assessing the seismic resistance of structures, rotor dynamics, the analysis of the instabilities of disc brakes of vehicles or aircraft wing, in detection of disorders or mechanical systems. He is an author of books and scientific articles devoted to the above-mentioned problems which were published in various national and international conferences.

Assoc. prof. Branislav Hučko, Ph.D., is an Associate Professor at the Institute of Applied Mechanics and Mechatronics, Faculty of Mechanical Engineering, Slovak University of Technology in Bratislava, Slovakia. He received a Dipl. Ing. Degree in Applied Mechanics in 1985 at STU Bratislava; and his Ph.D. Degree in Applied Mechanics at Slovak Academy of Sciences in Bratislava in 1991. Dr. Hučko took part in research projects funded by VEGA, KEGA and APVV Slovak scientific agencies, EU grant program TEMPUS, ATLANTIS EU - US grant and H2020 grant - the EMPIR Project "inTENSE". Dr. Hučko is a member of European Society of Biomechanics, IFTOMM, CEACM and SSM. His research activities concern on biomechanics, biomechatronics, tissue mechanics, experimental biomechanics, non-linear continuum mechanics, applications of FEM, engineering education. His works within this scope were published in textbooks, national and international journals and presented at many scientific conferences. 